\title{
Predictors of knowledge of puberty health among girl students
}

\author{
Atousa Afsari', Rohollah Valizadeh², Masoomeh Abbasnezhad ${ }^{3}$, \\ Parisa Rizehvandi ${ }^{4}$ and Samira Fatahi ${ }^{\text {* }}$ \\ 1,4,5 Master of Nursing, Operating Room Department, Kermanshah University of Medical Sciences, Kermanshah, Iran \\ ${ }^{2}$ MSc student of Epidemiology, Student Research Committee, Urmia University of Medical Sciences, Urmia, Iran \\ ${ }^{3}$ Master of Nursing, Nursing Department, Babol University of Medical Sciences, Mazandaran, Iran
}

\section{ABSTRACT}

Puberty and its consequence changes are one of the most important events of each person's life. Knowledge about puberty health lead to successful passage of this period. This study was aimed to determine factors predicting the knowledge of girl students about puberty health in Tabriz high schools. This study was a cross-sectional study conducted on 364 students in seventh and eighth grades in 2015. The participants were selected using random cluster sampling. Their knowledge and socio-demographic characteristics about puberty health were collected using selfcompleted questionnaires which is standardized questionnaire for Iran society. General Linear Model was used for determining the socio-demographic predictors of knowledge about puberty health. The mean score of students' knowledge was $8.26 \pm 2.21$ (in the range of $0-15$ scores). Fathers' education $(\mathrm{P}=0.023)$ and previous obtained information $(\mathrm{P}=0.001)$ were knowledge predictors. Regarding the mean score of students' knowledge and their direct relationship some factors such as father's education, it is suggested to increase the knowledge of parents especially mothers about puberty health by health providers at schools and the related organization using in present learning pamphlets, sessions and classes.

KEY WORDS: KNOWLEDGE, PUBERTY, GIRL STUDENTS

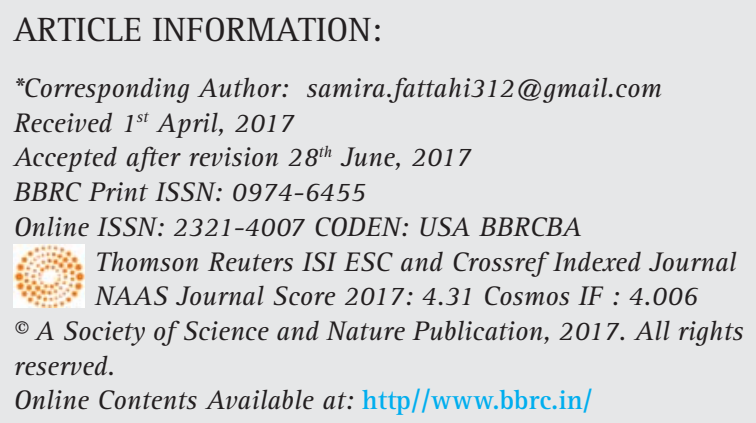




\section{INTRODUCTION}

According to the definition of World Health Organization (WHO), adolescence refers to 10-19 age groups (Russell \&t Robert,2005). Since adolescents are a great part of the population of the world, addressing various related issues of them is very important (Alavi, Poushaneh, Ct Khosravi,2009; Taghizadeh Moghaddam , et al, 2016). Based on statistics published by the Statistical Center of Iran, more than 20\% of the population (of approximately 80 million) consists of 10 to 19 yearold adolescents (Statistical Center, 2006; Valizade, Taymoori, Yousefi, et al, 2016 and Afsari et al., 2017).

Puberty is an important dimension of adolescence. Knowledge of its natural process and its problems successfully pass the individual to adulthood and fertility (Khakbazan, et al, 2008; Charkazi, et al, 2016). The health of girls in puberty is specifically important compared to boys. Puberty characteristics and specific physical and mental conditions of this period, related needs and their fundamental role in reproduction have a significant effect on their whole aspect of their life (Maleki, Delkhoush \&t Haji Amini, 2010).

Puberty is the predictable sequence of hormonal and physical changes, and these physical and physiological changes are critical in most girls and boys (Wong Et Baker, 1998). Puberty health includes principles and taking actions that result in maintenance and improvement of physical, mental, and emotional health during this period and requires education more than anything else (Malekshahi \&t Farhadi, 2006).

According to previous studies in Iran, most adolescent girls do not have enough information regarding menstruation health and most of them have unpleasant feelings about puberty and their first menstruation (Golchin, et al, 2012; Karimi, 1998). Sometimes, some of puberty problems put the person at crisis. Three main educational factors including family, school and society play active role in order to eliminate or reduce these problems (Kohstani, et al., 2010). Since the health of girls in present will supply the health of future generations, the conduction of vast studies on their knowledge and behavior about puberty health and efforts for increasing it, are kind of investments for achieving personal and social health (Charandabi, et al, 2014). Therefore, the present study has been tried to evaluate the knowledge of adolescent girls in seventh and eighth high school grades about puberty health.

\section{MATERIALS AND METHODS}

This study was a descriptive-analytical study conducted on 364 students in seventh and eighth grades in the first semester of the academic year (2015) in public and private girl secondary schools in Tabriz. Tabriz is a big city in North West of Iran. The participants were selected using random cluster sampling. Out of the 107 secondary schools for girls (67 public schools and 40 private schools besides schools for exceptional students) covered by the Offices of Education in the 5 districts of Tabriz, 8 public schools and 4 private schools were selected using the simple random sampling method. Regarding that the population of this study included 2,856 people, the size of the sample was considered 364 people using Morgan Table at 95\% confidence interval. One-third of seventh and eighth grades students in each school were randomly selected using a table of random digits, and students who had not experienced menstrual bleeding for more than 3 months, or who had taken part in similar research, were omitted. After participants' consent, the knowledge and socio-demographic characteristics questionnaires were filled by the students using one standard questionnaire that was standardized in Iran by different authors. The information was collected for one month from October 23, 2015 to November 23, 2015 in one shift from the secondary school girls in seventh and eighth grades.

The questionnaires used in studies conducted by Mohammad Alizadeh et al. were employed to complete the required information (Mohammad Alizadeh Charandabi, Mirghafourvand, Rahmani, et al, 2014; Mohammad Alizadeh Charandabi, Mirghafourvand, Saghi, et al, 2014). The content and face validity of these questionnaires (that included the three sections of sociodemographic characteristic, questions about knowledge, and questions about practice) were re-determined by asking the opinions of 11 faculty members of the Nursing and Midwifery school in Tabriz. First names and family names of the girls were not recorded on the questionnaires to keep anonymity.

The section on knowledge questionnaires included 15 questions with 4 possible answers for each one. One point was given to each correct answer, and a zero for a wrong answer or for an unanswered question. The questions were on physical health such as understanding puberty changes and the female reproductive system, nutrition during the puberty period, physical activity and rest, skin health, menstrual health, and mental health during puberty.

The section assessing practice of the girls included 32 items on physical health such as menstruation, nutrition, sports, and physical activity and on mental health. In fact, the students themselves reported their practice because direct observation of the practice related to puberty health in students was not possible. Each item was answered based on the 4 point Likert scale (never, sometimes, often, always) that received scores of 1 to 4 , respectively. Six items were scored inversely. The aspect of practice was not evaluated in this article. 
In both fields, the primary score of each individual and the total obtained scores were calculated and then, knowledge scores for each individual were considered very weak, weak, average, good, and excellent if they were less than $3.83,3.84$ to $6.49,6.50$ to $10.46,10.47$ to 12.67 , and more than 12.68 , respectively. The practice scores were also considered very weak, weak, average, good, and excellent if they were less than 72,72 to 81 , 82 to 101,102 to 111 and more than 112 , respectively. Inclusion criteria included having 13-14 year-old, having no mental disease, high school students and satisfaction to participate in the study. Exclusion criteria included participation in other classes related to puberty health and unwillingness to continue the participation in the study.

This study was approved by the Ethics Committee of Tabriz University of Medical Science (ID Code: 9381) and the objectives of the study were explained to all participants and all of them accepted to participate and were assured of the confidentiality of their individual information as well as the voluntary nature of participating in the study. SPSS version 13.0 was used for data analysis. In order to describe socio-demographic characteristics, knowledge about puberty health, descriptive statistics including frequency and percent, mean and standard deviation were used. In order to determine the relationship of the knowledge scores in area of puberty health with socio-demographic characteristics, the relationship was first measured using bivariate tests such as independent t-test and one-way ANOVA. Then, in order to determine the effect of each independent variable (socio-demographic characteristics) on the dependent variable (knowledge in area of puberty health), those variables whose significance were confirmed $(\mathrm{P}<0.05)$ in bivariate tests were inserted to the General Linear Model together. The significance level of $\mathrm{P}<0.05$ was selected.

\section{RESULTS AND DISCUSSION}

The socio-demographic characteristics of the participants are presented in Table.1. The mean age of participants were $12 \pm 3.6$ years old. The majority of students had experienced their first menstruation within the last 12 months. 57\% of the students were in seventh grade and $43 \%$ of them were in eighth grade from 364 students. The knowledge of the participants are shown in Table.2. The mean score of knowledge score was $8.3 \pm 2.2$ (in the range of 0-15 scores) that mean the students have average knowledge.

The results of bivariate tests showed that there was a relationship between knowledge score and the age of students $(\mathrm{P}=0.002)$, their parents' age $(\mathrm{P}=0.001)$, their fathers' education $(\mathrm{P}=0.001)$, previous obtained information $(\mathrm{P}=0.002)$, and the most preferred source of information $(\mathrm{P}=0.001)$. According to adjusted General Linear Model, fathers' education and previous obtained information had a significant relationship with knowledge that predicts 73\% percent of variance in knowledge scores (Table.3).

This study was aimed to determine factors predicting the knowledge of girl students about puberty health in Tabriz high schools. The mean score of students' knowledge was $8.26 \pm 2.21$ (in the range of 0-15 scores). There was a statistically significant relationship between knowledge and fathers' education and previous obtained information.

In this study, the high level of fathers' education has been associated with the high level of girls' knowledge. The high level fathers' education underlies cultural information exchange about puberty. These findings were in line with the results of the study done by Kazemi et al. and Abokoti et al. (Kazemi,2012; AbioyeKuteyi, 2000). In the present study, approximately 93\% of the participants argued that they have previously had knowledge but over half of them (60.1\%) considered their information as average regarding that previous obtained information is in direct relationship with knowledge, adequacy of information about puberty and most students said that their first source of information was their mother and a low percentage said that their source of information was health providers. Thus, the low level of mothers' knowledge and correct information or insufficient attention to puberty issues can be reasons behind the lack of knowledge of these adolescents. As noted in studies done by Abdollahi et al. (Âbdollahy, Shabankhanift Khani, 2004), Olfati et al. (Olfatict Aligholi,2008), Koff et al. (Koffet Rierdan, 2008), Afsari et al. (Afsari, Valizadeh, Fatahi, et al.2017), Valizadeh et al. in 2017 (Valizadeh, Taymoori, Yousefi, et al, 2016) Mohammadi et al. (Mohammadi, Ghajari, Valizade, et al, 2017) and Valizadeh et al. in 2016 (Valizadeh, Ghaajari, Ghaderi, 2016), there was a direct relationship between the amount of primary information and adequacy of information, and knowledge.

Knowledge of most teenage girls were weaker in comparison with puberty health. Furthermore, these some mentioned study indicated that their source of information were their mothers. Thus, strengthening the relationship between mothers and teenage daughters, removing the barriers such as shyness and embarrassment in expressing issues relating to puberty and menstruation by girls or mothers, indifference to lack of knowledge of the girls in issues related to puberty health and its consequences should be incorporated into educational courses. Thus, it is suggested to inform mothers with the adoption of proper and friendly methods of attracting trust, friendship and necessary attention related to puberty health. 
Table 1. Socio-demographic characteristics of participants in this study $(n=364)$

Age (year)

Variables

\begin{tabular}{|c|c|c|}
\hline Variables & Mean & SD \\
\hline Age of student & 12 & 3.6 \\
\hline Age of father & 41.7 & 10.09 \\
\hline Age of mother & 37.6 & 7.9 \\
\hline Illiterate & 20 & 5.5 \\
\hline Lower than diploma & 158 & 43.3 \\
\hline diploma and Higher than diploma & 145 & 39.8 \\
\hline licentiate and Higher than licentiate & 38 & 10.4 \\
\hline Illiterate & 12 & 3.3 \\
\hline Lower than diploma & 141 & 38.8 \\
\hline diploma \&t Higher than diploma & 145 & 39.8 \\
\hline licentiate \&t Higher than licentiate & 62 & 17 \\
\hline Housewife & 309 & 85.1 \\
\hline Employed & 22 & 6 \\
\hline Worker & 40 & 11 \\
\hline Clerk/retired & 117 & 32.1 \\
\hline Shopkeeper & 23 & 6.3 \\
\hline Private sector & 170 & 46.7 \\
\hline$>12$ & 227 & 62.5 \\
\hline $12-24$ & 82 & 26.6 \\
\hline$>24$ & 54 & 14.9 \\
\hline Both of father and mother & 338 & 94.2 \\
\hline Living with stepfather and mother & 4 & 1.1 \\
\hline Only with mother & 17 & 4.7 \\
\hline Yes & 332 & 91.5 \\
\hline Insufficient & 26 & 7.2 \\
\hline Moderate & 218 & 60.1 \\
\hline Sufficient & 103 & 28.4 \\
\hline Mother & 251 & 69 \\
\hline Health providers & 55 & 15.1 \\
\hline Magazines and books & 52 & 14.3 \\
\hline Mother & 234 & 64.5 \\
\hline Sister and Friends and peer group & 56 & 15.4 \\
\hline Health educator \&Teacher & 70 & 19.2 \\
\hline Fear and worry & 81 & 22.3 \\
\hline Shame and embarrassment & 120 & 33.1 \\
\hline Pride and happiness and enlargement & 54 & 14.9 \\
\hline Anger & 25 & 6.9 \\
\hline
\end{tabular}

Age at menarche

(each month)

Type of family

Previous acquisition information

Sufficiency of acquired information about puberty

Main source of information about puberty

Preferred source of information about puberty

Feeling at onset of menarche Anger

Table 2. Knowledge and practice of girl students about puberty health

\begin{tabular}{|l|l|l|l|}
\hline Characteristics & Range & Mean (SD)* & Minimum and maximum score \\
\hline Knowledge & $32-128$ & $92.3 \pm 10$ & $65-127$ \\
\hline
\end{tabular}


Table 3. Relationship between socio-demographic characteristics and Knowledge score in adolescent girls according to univariate and multivariate general linear model.

\begin{tabular}{|c|c|c|c|}
\hline \multicolumn{2}{|l|}{ Variables } & B (CI \%95)* & P-value \\
\hline \multirow{3}{*}{ Father's education } & Illiterate & $-1.5(-3.3$ to 0.2$)$ & 0.088 \\
\hline & Lower than diploma & $-8.4(-1.7$ to 0.7$)$ & 0.072 \\
\hline & $\begin{array}{l}\text { diploma \& Higher than diploma } \\
\text { licentiate \& Higher than licentiate }\end{array}$ & $-0.8(-1.6$ to -0.2$)$ & $0.023^{* *}$ \\
\hline $\begin{array}{l}\text { Previous acquisition } \\
\text { information }\end{array}$ & Yes & 2 (1 to 3.7 ) & $0.001^{* * *}$ \\
\hline \multirow{2}{*}{$\begin{array}{l}\text { Sufficiency of } \\
\text { acquired information }\end{array}$} & Insufficient & $-7(-11.2$ to -2.7$)$ & $0.001^{* * *}$ \\
\hline & Moderate & $-3.4(-5.8$ to -1.1$)$ & $0.003^{* * *}$ \\
\hline
\end{tabular}

${ }^{* *} \mathrm{P}$ value $<0.05$ showing the significance of variable of interest

The data collected was drawn from only in seventh and eighth grades. Another limitation was the small sample size of include studies as well as small size of participants.

\section{CONCLUSION}

Regarding the average knowledge of the participants in puberty health and also the effectiveness of family variables in the knowledge of the participants and also regarding that mothers are the most preferred and the first source of information about puberty health and menstruation-related issues, more attention should be paid to increasing parents' knowledge especially mothers, the how-about of information transfer and communication with the girls. In addition to training mothers, other proper and specialized educational sources such as health care providers, health care providers of schools, and the media by considering cultural and educational sensitivities.

The present article was extracted from MSc. thesis approved and sponsored by Tabriz University of Medical Sciences, Iran (ID Code: 9381). Hereby, the authors would like to thank the mothers and all the individuals who helped in conducting the study. The assistance of the head office of the Education Ministry of Tabriz City, the personnel from the girls' secondary schools, and participating students this study was greatly appreciated.

\section{REFERENCES}

Abdollahy F, Shabankhani B, Khani S. 2003 Study of puberty Health educational needs of adolesecents in Mazandaran province in 2003. JMUMS. 2004;14:56-63.

Abioye-Kuteyi EA.2000 Menstrual knowledge and practices amongst secondary school girls in Ile Ife, Nigeria. JRSH. 120: 23-6.
Afsari A, Valizadeh S, Fatahi S, Abbasnezhad M, Assdollahi M. 2017 Predictors of Knowledge and Practice of Girl Students about Puberty Health. Int J Pediatr 5(7): 5229-36. DOI:10.22038/ijp.2017.23081.1932.

Alavi M, Poushaneh K, Khosravi A. 2009 Puberty health: knowledge, attitude and practice of the adolescent girls in Tehran, Iran. Payesh 8:59-65.

Charkazi A, Berdi Ozouni- Davaji R, Bagheri D, Mansourian M, Qorbani M, Safari 0,2016 et al. Predicting Oral Health Behavior using the Health Promotion Model among School Students: a Cross-sectional Survey. International Journal of Pediatrics 2(2): 69-77.

Hagikhani Golchin N, Hamzehgardeshi Z, Fakhri M, Hamzehgardeshi L. 2012 The experience of puberty in Iranian adolescent girls: aqualitative content analysis. BMC Public Health 12:1-8.

Karimi E.1998 Investigate the attitude of mothers towards education of puberty problems in secondary school children, girls age between 11-14 years old Iranian. IJNMR. 18:74-9.

Kazemi Z. The Effect of Family Variables on Information Rate of Guidance School Female Students about Maturity Health. Family Research. 2012;8:319-35.

Khakbazan Z, Jamshidi F, Mehran A, Damghanian M. 2008 Effects of Lecture Presentation and Presenting Educational Packages on Girls' Knowledge About Adolescence Health. Journal of HAYAT. 2008;14:41-8.

Koff E, Rierdan J. 2008 Early adolescent girls' understanding of menstruation. Women Health. 12:1-19.

Kohstani H, Roozbahani N, Baghcheghi N. 2010 Experiences of puberty in adolescents: a qualitative study. IJNMR. 22:65.

Maleki A, Delkhoush M, Haji Amini Z, Ebadi A, Ahmadi K, Ajali A.2010 Effect of puberty health education through reliable sources on health behaviors of girls. JBS. 4:23-4.

Malekshahi F, Farhadi A. 2006 Knowledge, attitude and practice of high school girls on menstrual health. Yafteh 8:73-8.

Mohammad Alizadeh Charandabi S, Mirghafourvand M, Rahmani A, Seidi S, Saffari E, Mahini M, et al.2014 The effect 
of software on knowledge and practice of teenage girls toward puberty hygiene: a randomized controlled trial. IJME. 2:11021.

Mohammad Alizadeh Charandabi S, Mirghafourvand M, Saghi S, Seidi S, Rahmani A, Zareie S.2014 Practice of Iranian adolescent girls regarding puberty and menstrual hygiene and its predictors, Int J Women's Health Reproduction Sci. 2:196204.

Mohammadi S, Ghajari H, Valizade R, Ghaderi N, Yousefi F, Taymoori P, et al. 2017 Predictors of smoking among the secondary high school boy students based on the health belief model. Int J Prev Med 8:24. DOI: 10.4103/ijpvm.IJPVM_ 264_16

Olfati F, Aligholi S.2008 A study on educational needs of teenager girls regarding the reproductive health and determination of proper strategies in achieving the target goals in Qazvin. The Journal of Qazvin Univ of Med Sci. 12: 76-82.

Russell V, Robert B. 2005 ABC of adolescence. BMJ. 330:411.

Statistical Center of Iran. National Census of Population and Housing of Iran 2006. available from: http:amar.sci.org.ir.

Taghizadeh Moghaddam H, Shahinfar S, Bahreini A, Ajilian Abbasi M, Fazli F, Saeidi M.2016 Adolescence Health: the
Needs, Problems and Attention. International Journal of Pediatrics 4(2):1423-38.

Teen resource for advice, health information,social interaction 2004. Teen growth. available at: www.Teengrowth.com.

Valizade R, Taymoori P, Yousefi F, Rahimi L, Ghaderi N. The Effect of Puberty Health Education based on Health Belief Model on Health Behaviors and Pr 2016 eventive among Teen Boys in Marivan, North West of Iran. International Journal of Pediatrics 4(8):3271-81.

Valizadeh R, Taymoori P, Yousefi F, Rahimi L, Ghaderi N. 2016 The Effect of Puberty Health Education based on Health Belief Model on Health Behaviors and Preventive among Teen Boys in Marivan, North West of Iran. . Int J Pediatr 4(5): 1795-1805. DOI: 10.22038/IJP.2016.7167.

Valizadeh R, Ghaajari H, Ghaderi N, Yousefi F, Taymoori P, Ahmadi MA. 2016 Factors Related to Puberty Health in Male Students in the First Year of Undergraduate Second Grade in the City of Marivan Using health Belief Model: A Cross-sectional Study. Int J Prevent Public Health Sci 2(3):4-9. DOI: 10.17354/ijpphs/2016/32

Wong DL, Baker CM. 1988 Pain in children: comparison of assessment scales. Pediatr Nurs. 14(1):9-17. 